\title{
Ion Selectivity of Chromium Hydroxide and Chromium-Nickel Mixed Hydroxide Precipitate Membranes
}

\author{
Masao Sakashita and Norio Sato \\ Electrochemistry Laboratory, Faculty of Engineering, \\ Hokkaido University*
}

\begin{abstract}
Measurements of membrane potentials arising across chromium hydroxide and chromiumnickel mixed hydroxide precipitate membranes have been carried out to estimate the ion selectivity. The chromium hydroxide precipitate membrane showed a high selectivity for anions in electrolyte solutions of neutral $\mathrm{pH}$. The transport number of anions was evaluated to be $0.96-0.95$ in sodium chloride, nitrate, and perchlorate solutions. The fixed ion concentration on the membrane characterizing anion exchanger was determined to be about 0.1 g-equiv. $/ l$ by comparing the experimental membrane potentials with the theoretical values derived from the fixed charge theory of membranes. In sodium hydroxide solution, the transport number of $\mathrm{OH}^{-}$ions through the membrane was not constant but increased with decreasing solution $\mathrm{pH}$. The order of the selectivity for anions determined with the biionic potentials across the chromium hydroxide precipitate membrane was $\mathrm{Cl}^{-}>\mathrm{Br}^{-}>\mathrm{NO}^{-}{ }_{3}>\mathrm{I}^{-}>\mathrm{ClO}_{4}{ }^{-}$. This order of the selectivity differs significantly from the selectivity for the nickel hydroxide precipitate membrane. The biionic potential across the mixed hydroxide precipitate membranes of chromium and nickel shifted from that of nickel hydroxide to that of chromium hydroxide as the chromium concentration increased. The anion permeability estimated from the membrane potential arising across the biphase hydroxide membrane was very much smaller for the chromium hydroxide than for the nickel hydroxide precipitate membrane. This suggests that chromium is enriched on the surface of hydroxide particles constructing the mixed membranes.
\end{abstract}

\section{Introduction}

Corrosion films on a metal in aqueous solutions often exhibit a multi-phase structure. The exterior part of these films on the metal consists of precipitate products such as hydroxides or hydrous oxides of the metal. Under this circumstance, the precipitate layer acts as a gel-like electrolyte in contact to the oxide layer of the interior part of the corrosion films. Corrosion behaviors of the metal are, therefore, affected by the ion transport property through the precipitate layer from bulk solution to the interior oxide layer and vice versa.

If a precipitate film is allowed to be separated from a corroding metal, the ion selectivity in the film can be evaluated by measurement of the potential arising across the isolated membrane inserted between two electrolyte compartments of different concentration. It is however difficult in many cases to remove a corrosion precipitate film suitable for membrane potential measurement from the corroding metal surface, except for some special films such as $\mathrm{Al}_{2} \mathrm{O}_{3}$ on $\mathrm{Al}^{11}$ Alterna-

* Kita 13, Nishi 8, Kita-ku, Sapporo 060, Japan tively, precipitate membranes can be produced artificially on a cellulose sheet or on a paper, as have been described by many authors ${ }^{2-41}$ for inorganic membranes.

A few papers ${ }^{5,6)}$ have been reported on hydrous iron oxide precipitate membranes produced artificially in relation to the corrosion of iron and steels, in which the membranes were shown to be anionselective in sodium chloride solution. Nickel hydroxide precipitate membranes have also been found to be anion-selective, and the ion and water transport properties through the membranes have been studied in previous papers. ${ }^{7,81}$

In this work, membrane potentials arising across the chromium hydroxide precipitate membrane have been measured to evaluate the perm-selectivity of anions, the order of the selective transport among anion species, and the fixed ion concentration on the membrane. In order to compare the nickel and chromium hydroxide precipitate membranes in their perm-selective property, the membrane potentails across the mixed and biphase precipitate membranes of the hydroxides are also measured. 


\section{Experimental}

Chromium hydroxide precipitate membrane was formed on a cellulose sheet, sealed tightly between two compartments of a cell, by filling one compartment with $0.15 \mathrm{M} \mathrm{Cr}\left(\mathrm{NO}_{3}\right)_{3}$, and the other compartment with $0.2 \mathrm{M} \mathrm{NaOH}$. Mixed precipitate membranes of chromium and nickel hydroxides were prepared similarly by using mixed solutions of the nitrates. A minimum time of 3 days was allowed to complete the precipitation. A biphase precipitate membrane of chromium and nickel hydroxides was prepared by precipitation of chromium hydroxide on a nickel hydroxide precipitate membrane formed on a cellulose sheet. The membrane thickness was about $20 \mu \mathrm{m}$ for the chromium hydroxide and for the chromiumnickel mixed hydroxide. The biphase membrane consisted of a $0.5 \mathrm{~mm}$ layer of nickel hydroxide and a $20 \mu \mathrm{m}$ layer of chromium hydroxide. The membrane surface area was $0.5 \mathrm{~cm}^{2}$ for all the membranes.

After washing the membranes by flowing redistilled water, the electrolyte solutions were introduced into each compartment of the cell, and the potential difference was then measured in the cell of the type, $\mathrm{Hg} / \mathrm{Hg}_{2} \mathrm{Cl}_{2}$ /saturated $\mathrm{KCl}$-agar/electrolyte (I)/ membrane/electrolyte (II) saturated $\mathrm{KCl}$-agar/ $\mathrm{Hg}_{2} \mathrm{Cl}_{2} / \mathrm{Hg}$. In this measurement, the electrolyte solutions were flowed at $25 \mathrm{ml} \cdot \mathrm{min}^{-1}$ from solution reservoirs to the membrane surfaces. The temperature of solutions in the cell and the reservoirs was kept to $25 \pm 0.1^{\circ} \mathrm{C}$ with circulating water.

\section{Results}

The membrane potential is the potential difference arising across an ion exchange membrane which separates two solutions of the same electrolyte with different concentrations. According to Scatchard, ${ }^{9 \prime}$ it is expressed by

$$
\Psi_{\mathrm{I}}-\Psi_{\mathrm{II}}=-\frac{R T}{F} \int_{\mathrm{II}}^{\mathrm{I}} \sum_{i} t_{i} d \ln a_{i}
$$

in which $F$ is the faraday, $t_{i}$ the transference number of species $i, a_{i}$ the activity of species $i$ in solution, and $R$ and $T$ have their usual significances. The transport number, $T_{i}$, which is commonly used, is equal to $z_{i} t_{i}$, where $z_{i}$ is the valence of species $i$.

In the case where the transference of water is negligibly small, as has been discussed in a previous paper, ${ }^{8)}$ the membrane potential across the chromium hydroxide membrane in an aqueous solution comprizing only a cation and an anion is given by

$$
\Psi_{\mathrm{I}}-\Psi_{\mathrm{II}}=\frac{R T}{F}\left\{t_{+} \ln \frac{\left(a_{+}\right)_{\mathrm{II}}}{\left(a_{+}\right)_{\mathrm{I}}}+t_{-} \ln \frac{\left(a_{-}\right)_{\mathrm{II}}}{\left(a_{-}\right)_{\mathrm{I}}}\right\}
$$

Thus, the apparent transference numbers or transport numbers of the cation and anion can be estimated from variation of the membrane potential with the mean activity ratio.

Fig. 1 shows the membrane potentials across the chromium hydroxide membrane in sodium hydroxide and chloride systems, solution (I)/membrane/ solution (II), where the concentration of solution (I) was kept at $1 \times 10^{-2} \mathrm{M}$. In the sodium hydroxide system, the activity ratio is equivalent to the difference in $\mathrm{pH}$ value between solution (II) and (I): the solution (II) at the lowest $\mathrm{pH}$ value $(\mathrm{pH}=$ 10.7 ) in this system was made of magnesium oxide instead of sodium hydroxide.

It is evident that the variation of the membrane potentials with the activity ratio is markedly different in chloride and hydroxide solutions, such a difference was not observed in nickel hydroxide membranes. ${ }^{7)}$ For the chromium hydroxide

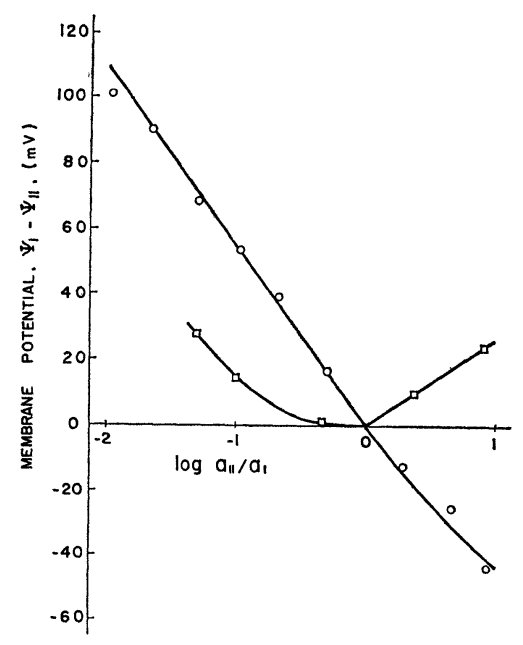

Fig. 1. Variation of membrane potential across chromium hydroxide precipitate membrane with the mean activity ratio of two solutions separated by the membrane.

(I)

(II)

$\mathrm{O}: \mathrm{NaCl}\left(1 \times 10^{-2} \mathrm{M}\right) \mid$ membrane $\mid \mathrm{NaCl}$ $\left(1 \times 10^{-4} \sim 1 \times 10^{-1} \mathrm{M}\right)$

(I)

$\square: \mathrm{NaOH}(\mathrm{pH}=11.9) \mid$ membrane | (II)

$\mathrm{NaOH}(\mathrm{pH}=11.0-12.8)$ or saturated $\mathrm{MgO}(\mathrm{pH}=10.7)$ 
membrane in sodium hydroxide solution, the transport numbers of $\mathrm{Na}^{+}$and $\mathrm{OH}^{-}$ions which are represented by the slope of membrane potential curve, depend on the solution concentration, $i$.e., on the $\mathrm{pH}$ value of the solution. The apparent transport number of $\mathrm{OH}^{-}$ions estimated from the slopes of the membrane potential against the activity ratio, increases from 0.27 to about 0.70 as the solution $\mathrm{pH}$ decreases from 13 to 10.7 .

In the sodium chloride system, on the other hand, the membrane potential decreases linearly with increasing the activity ratio. This negative slope evidently that the membrane is much more perm-selective for $\mathrm{Cl}^{-}$ions than for $\mathrm{Na}^{+}$ions. The apparent transport number of $\mathrm{Cl}^{-}$ions is estimated to be 0.96 . It was also estimated that the transport numbers of anions in sodium nitrate and perchlorate systems was about 0.95 . It appears therefore that the chromium hydroxide membrane is an anion exchanger in a uni-univalent electrolyte solution at neutral $\mathrm{pH}$.

According to the fixed charge theory of membranes, ${ }^{10,11)}$ the membrane potential of an anion selective membrane in a uni-univalent electrolyte solution is given by the following equation,

$$
\begin{aligned}
& \Psi_{\mathrm{I}}-\Psi_{\mathrm{II}}=\frac{R T}{F}\left\{\ln \frac{C_{1} \sqrt{4 C_{2}^{2}+\bar{X}^{2}}+\bar{X}}{C_{2} \sqrt{4 C_{1}^{2}+\bar{X}^{2}}+\bar{X}}\right. \\
& \left.-\bar{U} \ln \frac{\sqrt{4 C_{1}^{2}+\bar{X}^{2}}-\bar{X} \bar{U}}{\sqrt{4 C_{2}{ }^{2}+\bar{X}^{2}-\bar{X}} \bar{U}}\right\}
\end{aligned}
$$

where $\bar{U}=(\bar{u}-\bar{v}) /(\bar{u}+\bar{v}), \bar{u}$ and $\bar{v}$ are the mobilities of cation and anion in the membrane, $\bar{X}$ is the charge fixed on the membrane expressed in equivalents/liter, and $C_{1}$ and $C_{2}$ are the concentrations of the electrolyte in solution (I) and (II) separated by the membrane. The smooth curves in Fig. 2 show the membrane potentials calculated theoretically with equation (3) for an anion exchange membrane as a function of $C_{2}$ for different fixed charge concentrations $\bar{X}$ and for different mobility ratios $\bar{u} / \bar{v}$ at constant concentration ratio $C_{1} / C_{2}=10$. In Fig. 2, the measured membrane potentials across the chromium hydroxide precipitate membrane in sodium chloride system at $C_{1} / C_{2}=10$ are also shown by open circles. Since the theoretical curve for constant $\tilde{u} / \bar{v}$ value is shifted along the abscissa with decreasing $\bar{X}$ by an extent equal to $\log \bar{X}$, the values of $\bar{u} / \bar{v}$ and $\bar{X}$ for the membrane can be evaluated by means of the best-fit approach to the measured membrane potentials. The results thus obtained for the chromium hydroxide pre-

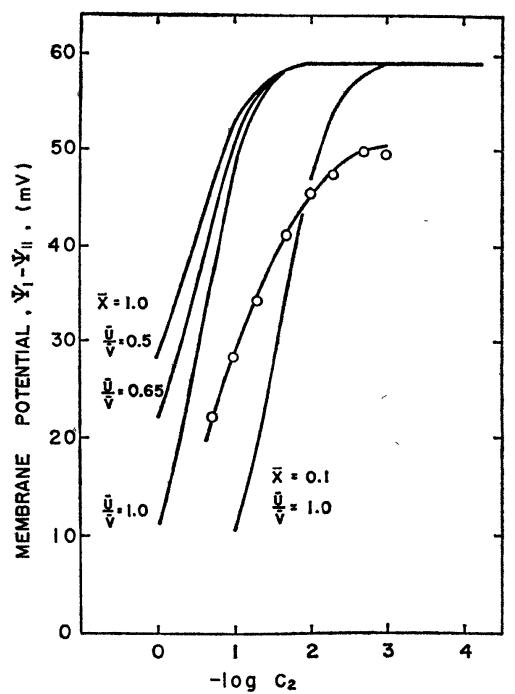

Fig. 2. Theoretical membrane potential for an anion exchange membrane in uni-univalent electrolyte and experimental membrane potential across chromium hydroxide precipitate membrane in $\mathrm{NaCl}$ solution at constant solution concentration ratio $\left(C_{1} / C_{2}=10\right)$ as function of $-\log C_{2}$.

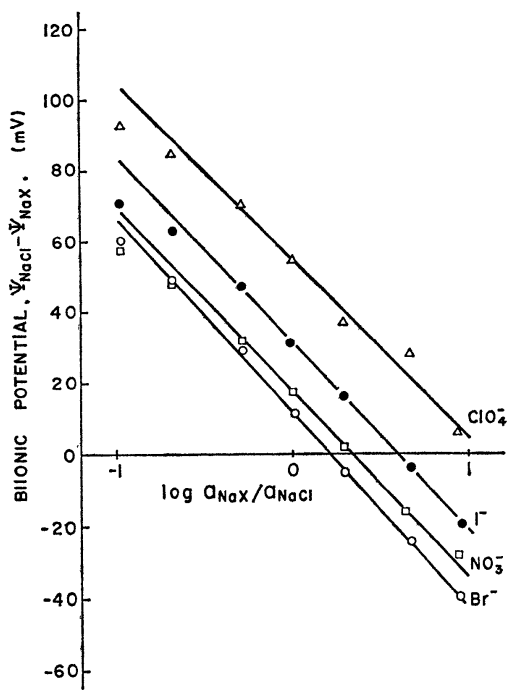

Fig. 3. Biionic potential across chromium hydroxide precipitate membrane in the system of $\mathrm{NaCl}\left(1 \times 10^{-2} \mathrm{M}\right) \mid$ membrane $\mid \mathrm{NaX}$ $\left(1 \times 10^{-3}-1 \times 10^{-1} \mathrm{M}\right)$.

O: $\mathrm{NaBr}, \square: \mathrm{NaNO}_{3}, \bullet: \mathrm{NaI}, \triangle: \mathrm{NaClO}_{4}$.

cipitate membrane are $\bar{X}=0.1$ and $\bar{u} / \bar{v}=0.5$. These values characterizing the membrane of chromium hydroxide are smaller than that of nickel hydroxide precipitate membranes reported previously. ${ }^{7}$ 
Figure 3 shows the biionic potentials across the chromium hydroxide membrane separating a standard $1 \times 10^{-2} \mathrm{M}$ sodium chloride solution from sodium bromide, iodide, nitrate, and perchlorate solutions of various concentrations. The biionic potential measured is different with different counter-ions (anions) and it is larger in all biionic systems than in the sodium chloride system shown in Fig. 1. These differences in the biionic potential obviously arise from different selectivities of the membrane for counter-ions.

As a measure of the selectivity of anions through precipitate membranes, the ratio of transference number of an anion to that of $\mathrm{Cl}^{-}$ion at the same activity has been chosen in a previous paper and named to the transport ratio. Provided that the transport number of anions is unity through the membrane, the transport ratio is given by the biionic potential in sodium salts systems as follows,

$$
\begin{aligned}
& \left(\frac{t_{\mathrm{X}}}{t_{\mathrm{C} 1}}\right)_{a_{\mathrm{X}}}=a_{\mathrm{C} 1} \\
& \quad=\exp \left\{-\frac{F}{R T}\left(\Psi_{\mathrm{NaCl}}-\Psi_{\mathrm{NaX}}\right)_{a_{\mathrm{X}}=a_{\mathrm{C} 1}}\right\}
\end{aligned}
$$

By definition and from Donnan equilibrium the transport ratio is given by,

$$
\left(\frac{t_{\mathrm{X}}}{t_{\mathrm{C} 1}}\right)_{a_{\mathrm{X}}=a_{\mathrm{C} 1}}=\left(\frac{\bar{v}_{\mathrm{X}} \cdot \bar{\gamma}_{\mathrm{C} 1}}{\bar{v}_{\mathrm{C} 1} \cdot \bar{\gamma}_{\mathrm{X}}}\right)_{a_{\mathrm{X}}=a_{\mathrm{C} 1}}
$$

where $\bar{\gamma} s$ are the activity coefficients of the anions in the membrane. The transport ratio of anions for the chromium hydroxide membrane estimated using equation (4) from the measured biionic potentials shown in Fig. 3 is listed in Table 1.

Figures 4 and 5 show the biionic potentials across the chromium-nickel mixed hydroxide membranes in $\mathrm{NaCl}\left(1 \times 10^{-2} \mathrm{M}\right) / \mathrm{membrane} / \mathrm{NaNO}_{3}\left(1 \times 10^{-3} \sim\right.$ $\left.1 \times 10^{-1} \mathrm{M}\right)$ and $\mathrm{NaCl}\left(1 \times 10^{-2} \mathrm{M}\right) /$ membrane/ $\mathrm{NaClO}_{4}\left(1 \times 10^{-3} \sim 1 \times 10^{-1} \mathrm{M}\right)$ systems. The chromium content in the mixed membranes investigated is represented by the atomic fraction of chromium and nickel, which was determined chemically by using an atomic adsorption spectrometer after dissolution of the membranes. The biionic

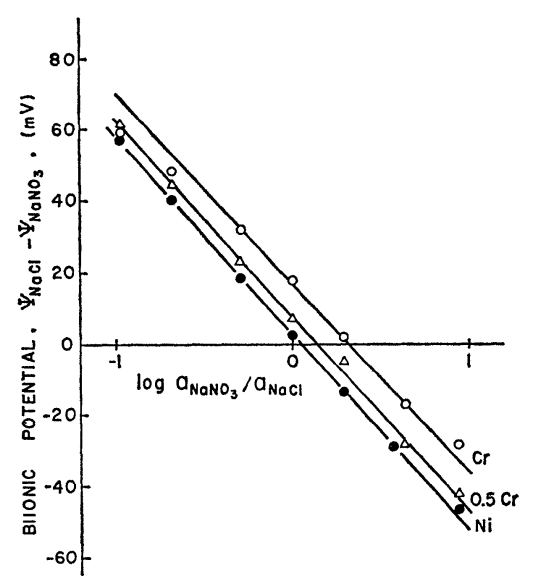

Fig. 4. Biionic potential across chromium-nickel mixed hydroxide precipitate membranes and non-mixed membranes in the system of $\mathrm{NaCl}\left(1 \times 10^{-2} \mathrm{M}\right) \mid$ membrane $\mid \mathrm{NaNO}_{3}$ $\left(1 \times 10^{-3}-1 \times 10^{-1} \mathrm{M}\right)$.

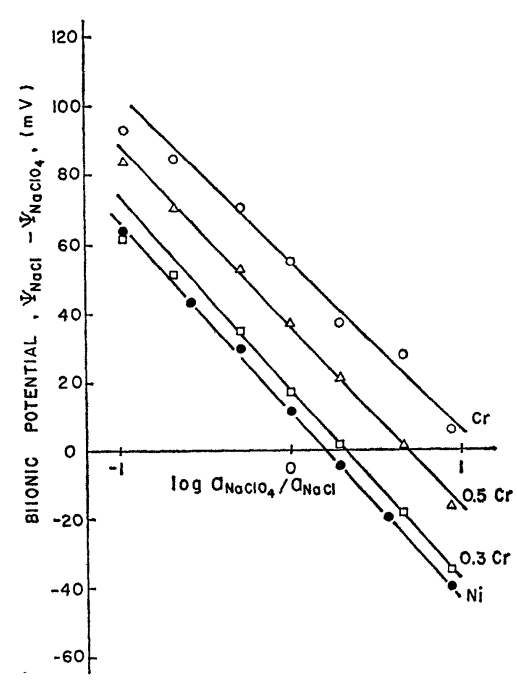

Fig. 5. Biionic potential across chromium-nickel mixed hydroxide membranes and nonmixed membranes in the system of $\mathrm{NaCl}$ $\left(1 \times 10^{-2} \mathrm{M}\right) \mid$ membrane $\mid \mathrm{NaClO}_{4}(1 \times$ $\left.10^{-3}-1 \times 10^{-1} \mathrm{M}\right)$.

Table 1. Transport ratio reffered to $\mathrm{Cl}^{-}$ions, $\left(t_{\mathrm{X}} / t_{\mathrm{C} 1}\right) a_{\mathrm{X}}=a_{\mathrm{C} 1}$ for chromium hydroxide, nickel hydroxide, and mixed hydroxide precipitate membranes.

\begin{tabular}{lccccc}
\hline \multirow{2}{*}{ Membrane } & $\begin{array}{c}\text { Atomic fraction } \\
\mathrm{Cr} /(\mathrm{Ni}+\mathrm{Cr})\end{array}$ & \multicolumn{4}{c}{$\left(t_{\mathbf{X}} / t_{\mathrm{Cl} 1}\right) a_{\mathbf{X}}=a_{\mathrm{Cl}=0.009}$} \\
\cline { 3 - 6 } & & $\mathrm{NO}_{3}{ }^{-}$ & $\mathrm{ClO}_{4}{ }^{-}$ & $\mathrm{Br}^{-}$ & $\mathrm{I}^{-}$ \\
\hline $\mathrm{Cr}(\mathrm{OH})_{3}$ & 1.0 & 0.52 & 0.12 & 0.61 & 0.29 \\
$0.5-\mathrm{Cr}$ & 0.50 & 0.73 & 0.24 & & \\
$0.3-\mathrm{Cr}$ & 0.31 & 0.88 & 0.51 & & \\
$\mathrm{Ni}(\mathrm{OH})_{2}$ & 0.0 & 0.91 & 0.70 & 1.17 & 1.10 \\
\hline
\end{tabular}


potentials across the chromium hydroxide and the nickel hydroxide membranes in the two systems are also shown in Figs. 4 and 5. From comparison of the biionic potentials across the mixed membranes and the non-mixed membranes, it is evident that the biionic potential of the mixed membranes changes from that of nickel hydroxide to that of chromium hydroxide as the chromium content increases. The transport ratios for the mixed membranes estimated using equation (4) in the same way as that described for nonmixed membranes are shown in Table 1.

In Table 1, the transport ratio for the nickel hydroxide membrane is also shown. Evidently, the order of anion selectivity of the chromium hydroxide membrane differs significantly from that of the nickel hydroxide.

Futhermore, in order to compare the permeability of an anion through the chromium hydroxide and nickel hydroxide membranes, the difference in permeability of $\mathrm{Cl}^{-}$ions, used in this work as the reference anion, has to be estimated. The difference in $\mathrm{Cl}^{-}$ion permeability between nickel hydroxide and chromium hydroxide can be estimated by measuring the membrane potential arising across a biphase membrane of chromium hydroxide and nickel hydroxide. In the $\mathrm{NaCl}$ $\left(1 \times 10^{-2} \mathrm{M}\right) / \mathrm{Ni}(\mathrm{OH})_{2} / \mathrm{Cr}(\mathrm{OH})_{3} / \mathrm{NaCl}\left(1 \times 10^{-2} \mathrm{M}\right)$ system, the membrane potential observed, $\Psi_{\mathrm{Ni}^{-}}$ $\Psi_{\mathrm{Cr}}$, was $57 \pm 5 \mathrm{mV}$. Since the transport number of $\mathrm{Cl}^{-}$ions across both membrane phases is close to unity, the membrane potential in this system can be presented in the anology of biionic potential theory as follows;

$$
\Psi_{\mathrm{Ni}}-\Psi_{\mathrm{Cr}}=-\frac{R T}{F} \ln \frac{\left(\bar{v}_{\mathrm{C} 1}\right)_{\mathrm{Cr}} \cdot\left(\bar{\gamma}_{\mathrm{C} 1}\right)_{\mathrm{Ni}}}{\left(\bar{v}_{\mathrm{C} 1}\right)_{\mathrm{Ni}} \cdot\left(\bar{\gamma}_{\mathrm{C} 1}\right)_{\mathrm{Cr}}}
$$

where $\left(\bar{v}_{\mathrm{C} 1}\right)_{\mathrm{Cr}}$ and $\left(\bar{v}_{\mathrm{C} 1}\right)_{\mathrm{Ni}}$ are the mobilities of $\mathrm{Cl}^{-}$ ions and $\left(\bar{\gamma}_{\mathrm{Cl}}\right)_{\mathrm{Cr}},\left(\bar{\gamma}_{\mathrm{Cl}}\right)_{\mathrm{Ni}}$ are the activity coefficients of $\mathrm{Cl}^{-}$ions in the chromium and nickel phases. Similarly to equation (5), the transport ratio of $\mathrm{Cl}^{-}$ ions across the chromium hydroxide and the nickel hydroxide membranes is defined by

$$
\frac{\left(t_{\mathrm{C} 1}\right)_{\mathrm{Cr}}}{\left(t_{\mathrm{C} 1}\right)_{\mathrm{N} i}}=\frac{\left(\bar{v}_{\mathrm{C} 1}\right)_{\mathrm{Cr}} \cdot\left(\bar{\gamma}_{\mathrm{C} 1}\right)_{\mathrm{Ni}}}{\left(\bar{v}_{\mathrm{C} 1}\right)_{\mathrm{Ni}} \cdot\left(\bar{\gamma}_{\mathrm{C} 1}\right)_{\mathrm{Cr}}}
$$

and is estimated to be 0.11 from the observed membrane potential using equation (6). By using $\left(t_{\mathrm{C} 1}\right)_{\mathrm{Cr}} /\left(t_{\mathrm{C} 1}\right)_{\mathrm{Ni}}$ and $t_{\mathrm{X}} / t_{\mathrm{C} 1}$ for both membranes shown in Table I, the transport ratio of other anions in both membranes, $\left(t_{\mathrm{x}}\right)_{\mathrm{Cr}} /\left(t_{\mathrm{X}}\right)_{\mathrm{N} 1}$, can be estimated to be 0.06 for $\mathrm{NO}_{3}{ }^{-}, 0.02$ for $\mathrm{ClO}_{4}{ }^{-}$, 0.05 for $\mathrm{Br}^{-}$, and 0.03 for $\mathrm{I}^{-}$. It is evident that the permeability of anions is very much smaller in the chromium hydroxide membrane than in the nickel hydroxide membrane.

\section{Discussion}

Generally, the perm-selectivity of ion exchange membrane is controlled by the selective transport of ions either across the membrane-solution interfaces or through the membrane. In the case of inorganic precipitate membranes of relatively large thickness with small mobilities for permiable ions, the ion transport that governs the perm-selectivity is likely to be through the membrane phase rather than across the membrane-solution interfaces. The main factors determining the selectivity in the membrane itself are the mobility and the concentration of permeable ions in the membrane. In accordance to the electroneutrality in the membrane, the concentration of permeable ions depends on the concentration and the sign of fixed ions on the membrane as well as the concentration of external electrolyte.

There is usually a fixed ionic charge on the surface of hydroxide particles constructing the membrane. The sign and the concentration of the surface ionic groups are influenced by the $\mathrm{pH}$ value and ionic species of the external solution. It is known that the surface charge of hydroxide is positive in solutions at $\mathrm{pH}$ more acidic than $\mathrm{pH}_{\mathrm{pze}}(\mathrm{pH}$ value of the point of zero charge) and is negative in solutions at $\mathrm{pH}$ less acidic than $\mathrm{pH}_{\mathrm{pzc}}$. Since $\mathrm{pH}_{\mathrm{pzc}}$ is $7.0-7.2$ for chromic oxide, ${ }^{12)}$ the surface charge on the chromium hydroxide precipitate membrane is probably negative in sodium hydroxide solution and positive in electrolyte solutions of neutral $\mathrm{pH}$ such as sodium chloride.

From this surface charge concept it might be expected that a relatively large transport number of $\mathrm{Na}^{+}$ions in sodium hydroxide solution shown in Fig. 1 arises from the negatively charged surface. However, the transport number of $\mathrm{Na}^{+}$ions was 0.30 at $\mathrm{pH} 11$ for chromium hydroxide indicating that the chromium hydroxide membrane is anionselective rather than cation-selective even in alkaline solutions the $\mathrm{pH}$ of which is larger than $\mathrm{pH}_{\mathrm{pzc}}$. It has also been observed that nickel hydroxide membranes are anion-selective in alkaline solutions of $\mathrm{pH}$ more basic than $\mathrm{pH}_{\mathrm{pzc}}$. It is therefore experimentally evident that metal hydroxide membrane in alkaline solutions can not always be regarded as having the cation exchange property.

In the membrane systems contacting with uniunivalent electrolyte solutions of neutral $\mathrm{pH}$ such as sodium chloride, the chromium hydroxide 


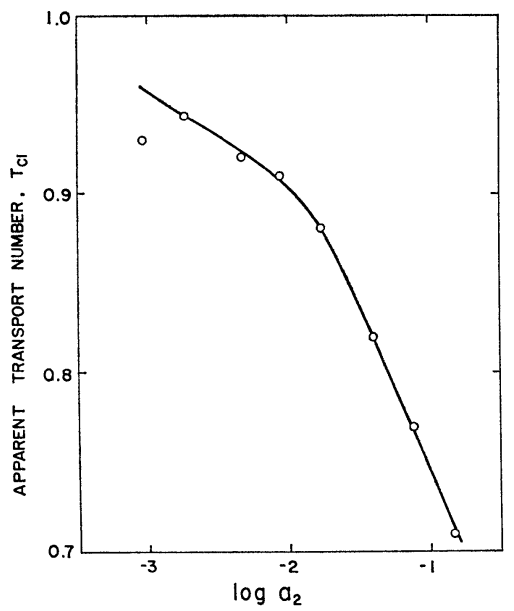

Fig. 6. Apparent transport number of $\mathrm{Cl}^{-}$ions, $T_{\mathrm{Cl}}$, calculated from measured membrane potentials in the system of $\mathrm{NaCl}\left(C_{1} \mathrm{M}\right)$ | membrane $\mid \mathrm{NaCl}\left(C_{2} \mathrm{M}\right)$ with $C_{1} / C_{2}=$ 10 , as a function of $\log a_{2}$.

membrane is a typical anion exchanger in all concentrations studied as shown in Fig. 1. The large transport numbers of anions are based on the large concentration of the fixed ions positively charged on the membrane. In solutions the concentration of which is larger than the fixed ion concentration, the transport numbers of anions gradually decreased with increasing concentration of co-ions (cations) in the membrane. Fig. 6 shows the apparent transport number of $\mathrm{Cl}^{-}$ions through the membrane in the sodium chloride solution system, calculated by using equation (2) from the results shown Fig. 2, as a function of $\log a_{2}$.

The biionic potential shown in Fig. 3 is the membrane potential arised from different permeabilities of counter-ions. The estimated order of the selectivity for univalent anion through the membrane is as follows, $\mathrm{Cl}^{-}>\mathrm{Br}^{-}>\mathrm{NO}_{3}{ }^{-}>\mathrm{I}^{-}>$ $\mathrm{ClO}_{4}{ }^{-}$. This order is markedly different from the order of mobility in aqueous solution and also from the order of selectivity in nickel hydroxide precipitate membranes, $\mathrm{Br}^{-}>\mathrm{I}^{-}>\mathrm{Cl}^{-}>\mathrm{NO}_{3}{ }^{-}>$ $\mathrm{ClO}_{4}^{-}$. The order of the selectivity, therefore, appears to be characteristic depending on the kind of precipitate membranes.

Besides the different in the order of the anion selectivity between the precipitate membranes of chromium hydroxide and nickel hydroxide, it is noticed that the transference of an anion differs with different membranes. Since the ratio of $\left(t_{\mathrm{X}}\right)_{\mathrm{Cr}} /\left(t_{\mathrm{X}}\right)_{\mathrm{N} 1}$ is much less than unity, the transference of an anion across mixed precipitate mem- branes may be determined predominantly by nickel hydroxide rather than chromium hydroxide. As is shown in Figs. 4 and 5, however, the biionic potential across mixed hydroxide precipitate membranes is very much dependent on the chromium concentration. It is therefore expected to occur that chromium is enriched on the surface of the particles constructing the mixed hydroxide precipitate membrane. The atomic fraction of chromium on the surface is approximately calculated to be 0.85 for the atomic fraction of chromium 0.3 in bulk and to be 0.95 for the atomic fraction of chromium 0.5 in bulk. This enrichment of chromium on the surface may be also supported by the fact that the growth rate of the mixed membranes in preparation is almost the same as that of non-mixed chromium hydroxide precipitate membranes about $20 \mu \mathrm{m}$ for three days, while the thickness of nickel hydroxide membranes reaches above $0.5 \mathrm{~mm}$ under the same preparation condition. The surface enrichment of chromium hydroxide is considered to reduce the growth rate of mixed hydroxide precipitate to the rate of nonmixed chromium hydroxide growth.

\section{Conclusion}

From measurements of the membrane potential arising across chromium hydroxide and chromiumnickel mixed hydroxide precipitate membranes prepared on a cellulose sheet, the following conclusions are obtained for the characteristics and the ion selectivity of the membranes;

1) The chromium hydroxide precipitate membrane shows a high selectivity for anions in electrolyte solutions of neutral $\mathrm{pH}$. The transport number of anions through the membrane is 0.96 0.95 .

2) The concentration of the fixed charge on the chromium hydroxide precipitate membrane is about 0.1 g-equiv. $l^{-1}$.

3) In alkaline solutions, the transport number of $\mathrm{OH}^{-}$ions is dependent on the solution $\mathrm{pH}$ and increases with decreasing solution $\mathrm{pH}$.

4) The order of selectivity for anions through the chromium hydroxide precipitate membrane is given as $\mathrm{Cl}^{-}>\mathrm{Br}^{-}>\mathrm{NO}_{3}{ }^{-}>\mathrm{I}^{-}>\mathrm{ClO}_{4}{ }^{-}$.

5) Enrichment of chromium hydroxide is expected to occur on the surface of particles constructing the mixed precipitate membrane of chromium hydroxide and nickel hydroxide.

\section{Acknowledgement}

One of the authors (M. S.) thanks the Sakkokai 
Foundations for scholarship.

(Received July 22, 1975)

\section{References}

1) K. Huber: Z. Elektrochem., 59, 693 (1955); N. Baba, M. Nakamura \& T. Yoshino: $J$. Metal. Finish. Soc. Japan, 26, 244 (1975).

2) P. Hirsch-Ayalon: Electrochim. Acta, 10, 773 (1965).

3) E. P. Honig \& J. H. Th. Hengst: ibid., 15, 491 (1970); 17, 75 (1972).

4) F. A. Siddiqi, N. Lakshminarayanaiah \& K. Saxena: Z. Physik. Chem. N.F., 72, 298 (1970); 72, 307 (1970).
5) I. Suzuki, N. Masuko \& Y. Hisamatsu: Corr. Eng. (Boshoku Gijutsu), 20, 319 (1971).

6) T. Ito: Nippon Kagaku Kaishi, 1213 (1974).

7) M. Sakashita \& N. Sato: Corr. Eng. (Boshoku Gijutsu), 24, 67 (1975).

8) M. Sakashita \& N. Sato: Electroanal. Chem., 62, 127 (1975).

9) G. Scatchard: J. Amer. Chem. Soc., 75, 2883 (1953).

10) T. Teorell: Proc. Soc. Exp. Biol. Med., 33, 192 (1935).

11) K. H. Meyer \& J.F. Sievers: Helv. Chim. Acta, 19, 649, 665, 987 (1936).

12) G. A. Parks: Chem. Rev., 65, 177 (1965) 